\title{
The contribution of satellite SAR-derived displacement measurements in landslide risk management practices
}

\author{
Federico Raspini $^{1} \cdot$ Federica Bardi $^{1} \cdot$ Silvia Bianchini $^{1}$ • \\ Andrea Ciampalini $^{1} \cdot$ Chiara Del Ventisette ${ }^{1}$. \\ Paolo Farina $^{2} \cdot$ Federica Ferrigno $^{1} \cdot$ Lorenzo Solari $^{1}$. \\ Nicola Casagli ${ }^{2}$
}

Received: 15 July 2016/Accepted: 15 November 2016/Published online: 29 November 2016

(C) The Author(s) 2016. This article is published with open access at Springerlink.com

\begin{abstract}
Landslides are common phenomena that occur worldwide and are a main cause of loss of life and damage to property. The hazards associated with landslides are a challenging concern in many countries, including Italy. Over the last 15 years, an increasing number of applications have aimed to demonstrate the applicability of images captured by space-borne Synthetic Aperture Radar (SAR) sensors in slope instability investigations. InSAR (SAR interferometry) is currently one of the most exploited techniques for the assessment of ground displacements, and it is becoming a consolidated tool for Civil Protection institutions in addressing landslide risk. This paper presents a subset of
\end{abstract}

Federico Raspini

federico.raspini@unifi.it

Federica Bardi

federica.bardi@unifi.it

Silvia Bianchini

silvia.bianchini@unifi.it

Andrea Ciampalini

andrea.ciampalini@unifi.it

Chiara Del Ventisette

chiara.delventisette@unifi.it

Paolo Farina

paolo.farina@geoapp.it

Federica Ferrigno

federica.ferrigno@unifi.it

Lorenzo Solari

lorenzo.solari@unifi.it

Nicola Casagli

nicola.casagli@unifi.it

1 Earth Sciences Department, University of Firenze, Via La Pira 4, 50121 Florence, Italy

2 Geoapp s.r.1., Academic Spin-off of the University of Florence, Via Veracini 30, 50144 Florence, Italy 
the results obtained in Italy within the framework of SAR-based programmes and applications intended to test the potential application of C- and X-band satellite interferometry during different Civil Protection activities (namely prevention, prevision, emergency response and post-emergency phases) performed to manage landslide risk. Analysis of satellite SAR data is demonstrated to play a major role in the investigation of landsliderelated events at different stages, including detection, mapping, monitoring, characterization and prediction. In addition, this paper also discusses the limitations that still exist and must be overcome in the coming years to manage the transition of satellite SAR systems towards complete operational use in landslide risk management practices.

Keywords SAR interferometry $\cdot$ Speckle tracking $\cdot$ Landslide risk $\cdot$ Civil Protection

\section{Introduction}

Landslides, a term that encompasses a wide variety of surface deformations and displacements, are natural or human-induced phenomena that occur worldwide in mountainous and hilly regions and represent the main process by which natural slopes evolve. The hazards associated with landslides result in complex and changing landscapes whose evolution must be mapped and monitored in detail to forecast future behaviour. Landslide and debris-flow disasters represent a major geological hazard that occurs more frequently worldwide than volcanic eruptions and floods and is nearly as common as earthquakes (IGOS 2004). Among natural hazards, landslides are one of the main causes of loss of life and property (Canuti et al. 2004), claiming fatalities and injuries and producing direct and indirect economic losses. Human activities also play an important role in increasing the potential impact of landslides. Despite the ubiquitous character of landslides, the resultant magnitude of human loss is poorly quantified (Petley 2012) for two major reasons: (1) systematic data collection is lacking (Petley 2010) and (2) fatalities associated with landslides are often overlooked because they are often associated with other major natural disasters that occur simultaneously (Hervás 2013). The global impact of slope failures on structures, infrastructure, the economy and the environment remains largely undetermined (Schuster and Fleming 1986), and it is difficult to quantify at the European scale as well (Hervás 2013). To represent landslide risk on a global scale, a few attempts have been made to assess susceptibility, hazard and risk with uncertain degrees of accuracy (Nadim et al. 2006).

Italy is one of the European countries with the highest landslide hazard, and $13 \%$ of the territory is prone to landslides, according to Dilley et al. (2005) and Nadim et al. (2006). In Italy, detailed records of landslides do exist, such as the IFFI (Italian Landslide Inventory, Inventario dei Fenomeni Franosi in Italia), which mapped over 490,000 landslides covering an area of $21,200 \mathrm{~km}^{2}$, equal to $7 \%$ of the total surface (Trigila et al. 2014). Approximately 9600 areas in Italy have been classified as "at extremely high landslide risk" according to Italian Law No. 267/1998. By exploiting catalogues of historical landslides in Italy, Guzzetti (2000) and Salvati et al. (2010) analysed the related impact and assessed individual and societal risks at the national scale. Between 1990 and 1999, at least 263 people were killed by mass movements for an average of 26 deaths per year. In the twentieth century and the first decades of the twenty first century, several landslides injured or killed more than 8000 people, destroying public buildings and private houses and 
resulting in over 200,000 people homeless or evacuated (Salvati et al. 2015). The total cost of direct damage is estimated to range annually from 0.3 to $0.4 \%$ of the gross domestic product (Canuti et al. 2004), highlighting that the landslide problem in Italy is particularly relevant, and on a worldwide scale, it is second only to Japan among the technologically advanced countries.

In this framework, the Civil Protection authorities (CPAs), who are appointed to prevent landslide hazards and to manage emergencies deriving from potentially damaging events, need a monitoring strategy that uses reliable data acquired in a short period of time over wide areas (at times covering entire regions) for use in forecasting, prevention and emergency phases. Earth Observation (EO) data and remote sensing play a key role in management of geohazard-related problems, leading to new levels of understanding of the complex solid Earth processes that often lead to disasters. In recent decades, satellite-based observations and the derived geospatial products have been successfully demonstrated to be highly valuable in measurement of land motion in a wide range of application fields (Tralli et al. 2005), including land motions related to landslides (Tofani et al. 2013). EO technologies have broadened their range of applications with the development of techniques based on exploitation of the phase and amplitude information contained in satellite SAR images. In particular, multi-interferogram approaches have proven their valuable contributions in different phases of landslide response (Canuti et al. 2007) and Civil Protection practices (Corsini et al. 2006; Farina et al. 2007). In the last most recent decade, the Italian Civil Protection Department (DPC), in collaboration with the Department of Earth Sciences of the University of Firenze (DST-UNIFI), established satellite SAR-based programmes and applications aimed at managing the transition from research to enhanced operational capability in landslide risk management.

This paper focuses on the results derived from application of satellite SAR-based techniques within the abovementioned projects and applications. To demonstrate the reliability and usefulness of these techniques in different aspects and stages of landslide management, six case studies from Northern to Southern Italy are presented. These real cases summarize the potential contribution of InSAR data for analysis of different slope movements. InSAR is confirmed as a valuable support for landslide investigations at different scales (from the regional to local scale), in different situations (real, near real and deferred time), and during the main Civil Protection phases, namely the pre-disaster phase, the response phase and the post-disaster phase.

\section{Ground deformation retrieval with satellite SAR images}

SAR images include both amplitude and phase information. In the last fifteen years, the phase information from SAR images obtained by instruments on board satellites was exploited using the InSAR approach, a method specifically devised, designed and implemented to measure changes in signal phase over time (Rosen et al. 2000; Massonnet and Feigl 1998). The first algorithm specifically implemented to process a long series of SAR images is the PSInSAR (Permanent Scatterer InSAR) (Ferretti et al. 2000, 2001), which analyses long stacks of co-registered SAR images to identify (within the ground resolution cell of the satellite) common point-wise targets in each SAR scene (the so-called PS, Permanent Scatterers), that reliably and persistently reflect the radar signal back to the sensor during the entire acquisition interval. The phase information backscattered from these coherent points is used to derive the ground displacement along 
the sensor's LOS (Line of Sight) and the temporal evolution of the movement. Indeed, unlike the conventional single-pair differential interferometry (DInSAR), Advanced DInSAR relies on multi-interferometric approaches and allows construction of time series of displacement with sub-millimetre accuracy for every coherent point (Ferretti et al. 2007a, b).

The millimetre accuracy and high temporal and areal density of points, especially in urbanized areas, make multi-interferogram approaches ideally suited to the analysis of slow-moving landslides. Over the last two decades, since the pioneering application by Fruneau et al. (1996), geoscientists have exploited SAR data for landslide detection and mapping (Kimura and Yamaguchi 2000; Farina et al. 2006; Bianchini et al. 2012; Hölbling et al. 2012; Raspini et al. 2013; Bardi et al. 2014), characterization and monitoring (Tofani et al. 2013; Del Ventisette et al. 2013; Bovenga et al. 2012), detection of trend changes in general landslide movement (Cigna et al. 2011) or to highlight sectors with different velocities and behaviour within the landslide area (Cigna et al. 2012a, b; Berti et al. 2013). Due to the limitations of current space observation systems (satellite revisiting time and wavelength), the reliable applicability of multi-interferometric approaches is currently restricted only to landslides with notably slow dynamics (i.e. extremely slow and very slow movements, according to the Cruden and Varnes (1996) classification scheme). High spatial displacement gradients, rates of movements that exceed the threshold values, temporally variable velocities and areas of low coherence due to vegetation coverage are known to hinder exploitation of InSAR data.

Analysis of amplitude information (rather than the phase values of the SAR scene) is an effective alternative to InSAR for mapping surface deformation in the case of temporal decorrelation (Michel et al. 1996) and/or loss of coherence (Strozzi et al. 2002) occurring between two time-adjacent SAR acquisitions. Typical applications include mapping of glacier/rock glacier flows and large co-seismic fault slips. In these situations, rapid changes in ice surfaces and the large deformation gradients across seismic faults lead to failure of the InSAR approach (Singleton et al. 2014). To date, only a small number of studies have used pixel-offset techniques for monitoring slope movements (Manconi et al. 2014; Bhattacharya et al. 2015).

Amplitude-based methods exploit correlation of the speckle pattern of two images (pre- and post-failure) to map the deformation induced by rapid landslides in a densely vegetated area. By tracking amplitude features in multi-temporal SAR data, the speckletracking methods are capable of recording movement rates (from tens of centimetres to tens of metres) that exceed those observable with SAR interferometry (Raspini et al. 2014; Paradella et al. 2015). The local image offsets (both in the slant range and azimuth directions) can be successfully estimated depending on the presence of nearly identical features in the two SAR images. The precision of techniques based on cross-correlation of amplitude data is on the order of 1/50th to 1/20th of the image pixel (De Zan 2014), depending on the coherence level and the number of pixels inside the window used in the analysis. The attainable precision is lower than that obtained by applying the InSAR approach to phase data. However, speckle tracking can be successfully applied to areas affected by high displacement rates, which would appear completely uncorrelated in any SAR interferogram. Moreover, with respect to interferometry, which is capable of retrieving only 1D displacement data, unless information acquired from two geometries (ascending and descending) is combined, by combining two acquisition geometries, speckle tracking offers three components of the displacement vector (east-west, updown and north-south). 


\section{Risk management strategy}

The documented increase in the frequency and occurrence of landslides in Italy (Nadim et al. 2006), associated with growing urbanization and uncontrolled land use has led to the design and implementation of a complete strategy for effective management of the associated hazard and risk at a national level. Since its institution in 1992, the DPC has taken a guiding role in protecting the population and safeguarding the environment from the damages and dangers posed by natural catastrophes in Italy. The DPC operates according to prevention and forecasting, early warning and alerting, emergency response and recovery from emergency (Pagliara et al. 2014). In particular, four Civil Protection activities can be listed: (1) risk prevention, (2) risk prevision, (3) emergency response and (4) post-emergency activity. Prevention and prevision are the pre-event phases primarily concerned with strategies designed to reduce the potential risks caused by landslide occurrence. Emergency response and post-emergency activities are conducted when an event affects a given territory and are devoted to combating the effects, overcoming the emergency and restoring the previous conditions.

The prevention phase addresses risk preparedness and consists of activities intended to reduce or minimize the potential occurrence of damages due to hazardous events. Prevention activities range from risk assessments of the territory to adoption of measures to reduce risk, to the definition of risk scenarios. Preventative measures for risk reduction base their effectiveness on knowledge of the territory under investigation and include detailed characterization of landslide-prone areas and the provision of maps or inventories (e.g. landslide inventory maps) of areas that are or might be at risk.

The prevision phase aims at forecasting potential ground deformation events. In this phase, activities rely on collecting information on the deformation events under investigation and processing and interpreting the collected data according to models. This activity allows detection of the areas most prone to hazardous events and identification of the most important expected phenomena and the consequent effects for design of effective monitoring and early-warning systems.

The emergency response phase includes all activities devoted to an efficient response to calamities, i.e. rescue of the affected population and organization of prompt interventions for citizen safety and environmental conservation purposes.

The post-emergency phase encompasses recovery activities necessary to restore the previous living conditions. In this phase, the main actions are performing residual risk zonation and establishing mitigation plans and long-term surveillance to reproduce the same or better living conditions existing before the disrupting event.

The use of satellite SAR technologies, which are eventually integrated with conventional methods for landslide investigations ("radar-interpretation" according to Farina et al. 2007), can greatly support landslide risk management activities performed both in real and deferred time, throughout all of the emergency cycle phases. In the following sections, we describe how radar interpretation can be inserted into different steps of a Civil Protection framework and refer to selected examples of landslides in Italy (Fig. 1). With respect to geohydrological hazards, the basic requirement for any effective prevention phase is knowledge of the territory. In this phase, satellite SAR data can support all activities necessary to collect information on slope movements in terms of location, extent, and activity for use as a support in definition of the appropriate prevention strategies, risk scenarios and adoption of land-use planning. Information on the hazards that threaten a community is the basic instrumental tool that aids authorities in avoiding or at least 

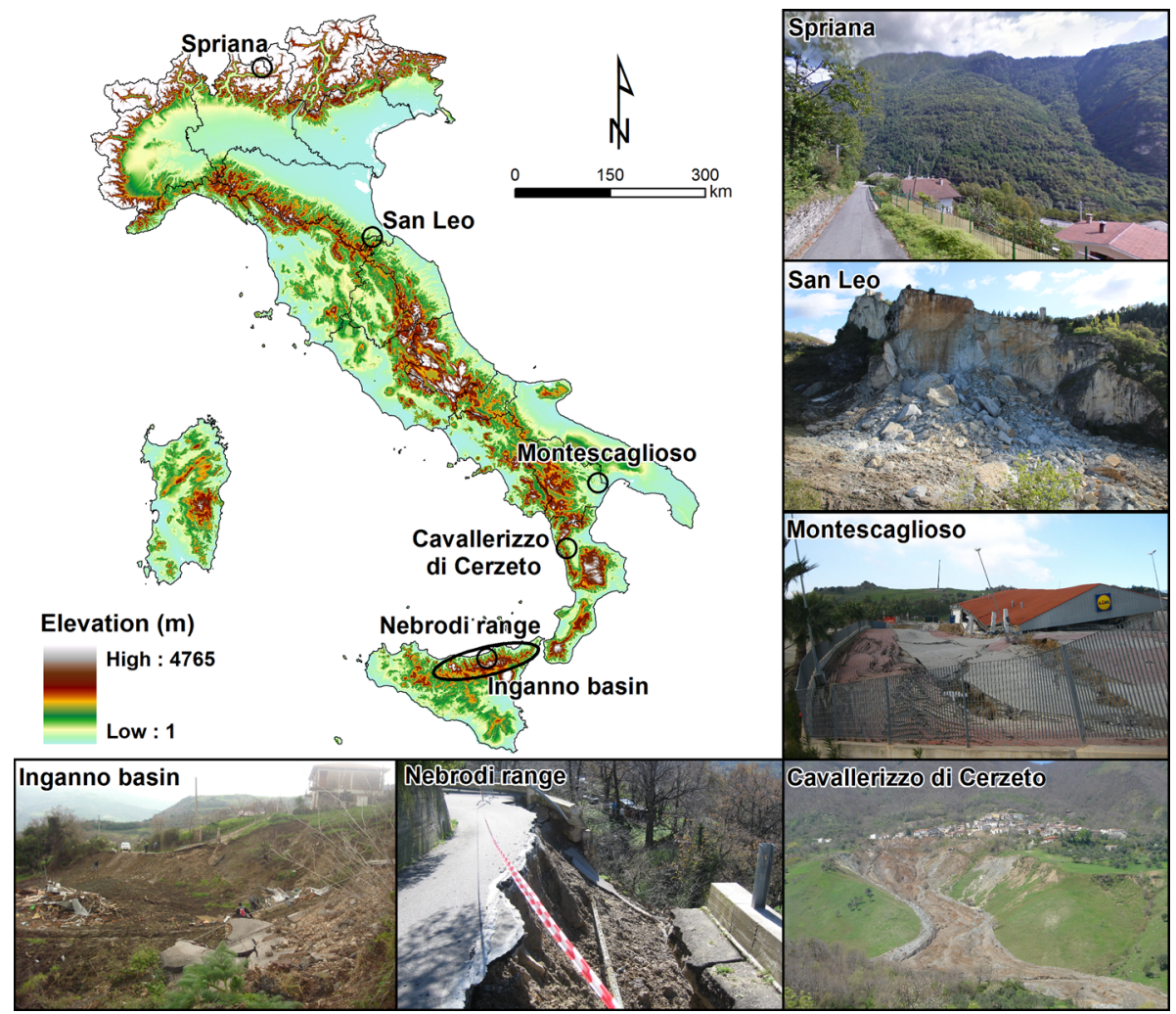

Fig. 1 Location of the six case studies analysed for DPC and presented in this paper

minimizing risks. The analysis can be applied at different spatial scales to detect single or multiple landslides covering small to notably large areas.

\section{Prevention of landslide risk}

Following the principle adopted by geomorphologists of "the past and the present are keys to the future" (Carrara et al. 1995; Aleotti and Chowdhury 1999; Guzzetti et al. 1999, 2012), landslides are more likely to occur under the conditions that determined past instabilities. In this sense, detection and mapping of existing landslides are crucial in improvement of landslide risk knowledge and consequently in assessment of landslide risk.

\subsection{Basin scale: LIM updating-The Furiano basin (Sicily Region) case study}

At a regional/basin scale, Landslide Inventory Maps (LIMs) and their updates rely on identification of past landslides (extension, distribution, types and state of activity) in a specific region and the elements at risk to furnish basic information for proper prevention activities. LIMs represent the basic element used to evaluate landslide susceptibility, hazard, vulnerability and risk. 
Since 1992, when the first advanced SAR satellite (ERS-1) was launched, SAR data have been available for use in compiling/updating inventory maps. Satellite InSAR, which couples wide coverage and high precision measurements, allowed the retrieval of ground movement measurements in urban and peri-urban areas. Currently, detection and mapping of slow-moving landslides finds valuable support in long-time historical archives of SAR data. The PSInSAR technique (Ferretti et al. 2001) and its evolution to the SqueeSAR approach (Ferretti et al. 2011) represent effective tools for accurately mapping, monitoring and analysing ground motions in natural terrains (Raspini et al. 2013). LIMs obtained from satellite data are based on average LOS velocity values registered by sensors during their subsequent acquisitions. These inventories are able to offer qualitative (e.g. state of activity) and quantitative (e.g. intensity) information on each detected phenomenon. Stateof-activity estimation of each landslide can be based on an "activity matrix" (Cigna et al. 2013) that considers the average LOS velocity of the analysed SAR data (Del Ventisette et al. 2014) or alternatively on a comparison between the mean LOS velocity detected by older available data sets and the mean LOS velocity obtained using the more recent ones (Righini et al. 2012).

This type of approach has been adopted to update the landslide inventory map of Inganno creek, a highly prone area in the Messina province along the Tyrrhenian coast. The Messina province was considerably affected by mass movements between 2009 and 2010 as a consequence of several rainfall events that triggered hundreds of landslides, causing severe damage to buildings and infrastructures.

A pre-existing LIM of this area dated up to 2012 was available, including 114 landslides for a total area of $9.1 \mathrm{~km}^{2}$ (AdB Sicilia 2012). This LIM was the result of a detailed field survey combined with analysis of aerial stereoscopic images. Despite the good accuracy of the available LIM, a brief analysis of the PSInSAR data showed that several areas originally mapped as stable were actually affected by ground deformation phenomena. Furthermore, most of the mapped landslides were not updated in terms of state of activity. Updating of the LIM has been conducted primarily using four different available satellite SAR data sets. These data were acquired with different satellite SAR sensors (Radarsat-1 and COSMO-SkyMed) during different time periods (Table 1). The images were processed with the SqueeSAR approach. Radar interpretation was supported by photo-interpretation of aerial photographs acquired in 1954, 1955 and 2005. A field survey was performed to validate the PSInSAR and photo-interpretation results.

The combined use of photo-interpretation and the availability of different SAR data sets produced the following: (1) detection of new landslides with respect to those included in the pre-existing LIM, (2) refinement of the boundaries of several pre-existing landslides and (3) evaluation of the state of activity of those landslides, including measurement points. The updated LIM includes a total of 152 events: 3 rockfalls and topples, 58

Table 1 Characteristics of SAR data sets used in updating of the LIM

\begin{tabular}{lllllllc}
\hline Satellite & Agency & Band & Geometry & $\begin{array}{l}\text { Revisiting } \\
\text { time (days) }\end{array}$ & Temporal range & $\begin{array}{l}\text { No. } \\
\text { scenes }\end{array}$ & $\begin{array}{l}\text { PS density } \\
\left(\mathrm{PS} / \mathrm{km}^{2}\right)\end{array}$ \\
\hline Radarsat-1 & CSA & $\mathrm{C}$ & Ascending & 24 & $30 / 12 / 05-26 / 01 / 10$ & 46 & 112.73 \\
Radarsat-1 & CSA & $\mathrm{C}$ & Descending & 24 & $31 / 01 / 06-03 / 02 / 10$ & 47 & 86.86 \\
CSK & ASI & $\mathrm{X}$ & Ascending & 16 & $01 / 05 / 11-03 / 115 / 12$ & 26 & 219.85 \\
CSK & ASI & $\mathrm{X}$ & Descending & 16 & $16 / 05 / 11-02 / 05 / 12$ & 32 & 400.62 \\
\hline
\end{tabular}

CSA Canadian Space Agency, ASI Italian Space Agency, CSK COSMO-SkyMed 
complex landslides, 23 flows and 68 slides for a total area of $26.1 \mathrm{~km}^{2}\left(+17.0 \mathrm{~km}^{2}\right.$ with respect to the pre-existing LIM). In additional detail, the landslide area was enlarged for 37 records, 35 records were confirmed, and 80 new landslides were identified (Fig. 2). Based on the SAR data, 49.2 and $21.8 \%$ of the mapped landslides have been classified as active and inactive, respectively, and $29 \%$ of the events are classified as not determined because of the lack of interferometric data.

\subsection{Local scale: single landslide characterization-The Spriana (Lombardia Region) case study}

On a local scale, i.e., at the single landslide level, the prevention phase is devoted to identification of the instability conditions to better understand the dynamics of the phenomenon. The availability of almost 20 years of continuous SAR acquisitions on a monthly scale offers comprehensive knowledge of the landslide and valuable information for risk management scenarios (Bardi et al. 2016). This approach was used in the Spriana landslide in which the multi-temporal dynamics of the phenomenon were first analysed, and a possible risk scenario related to the formation of a landslide dam at the base of the slope was subsequently considered. The Spriana landslide is located $4 \mathrm{~km}$ north of the city of Sondrio and affects the steep slope that constitutes the left bank of the Mallero River over an area of $0.6 \mathrm{~km}^{2}$, a total length of $700 \mathrm{~m}$ stretching from 1400 to $700 \mathrm{~m}$ a.s.l., and with an estimated unstable mass of more than $50 \mathrm{Mm}^{3}$ (Longoni et al. 2014; Agliardi and Crosta 2015). Beginning in the early nineteenth century, several landslide reactivations and accelerations were documented (Belloni and Gandolfo 1997). The most important events
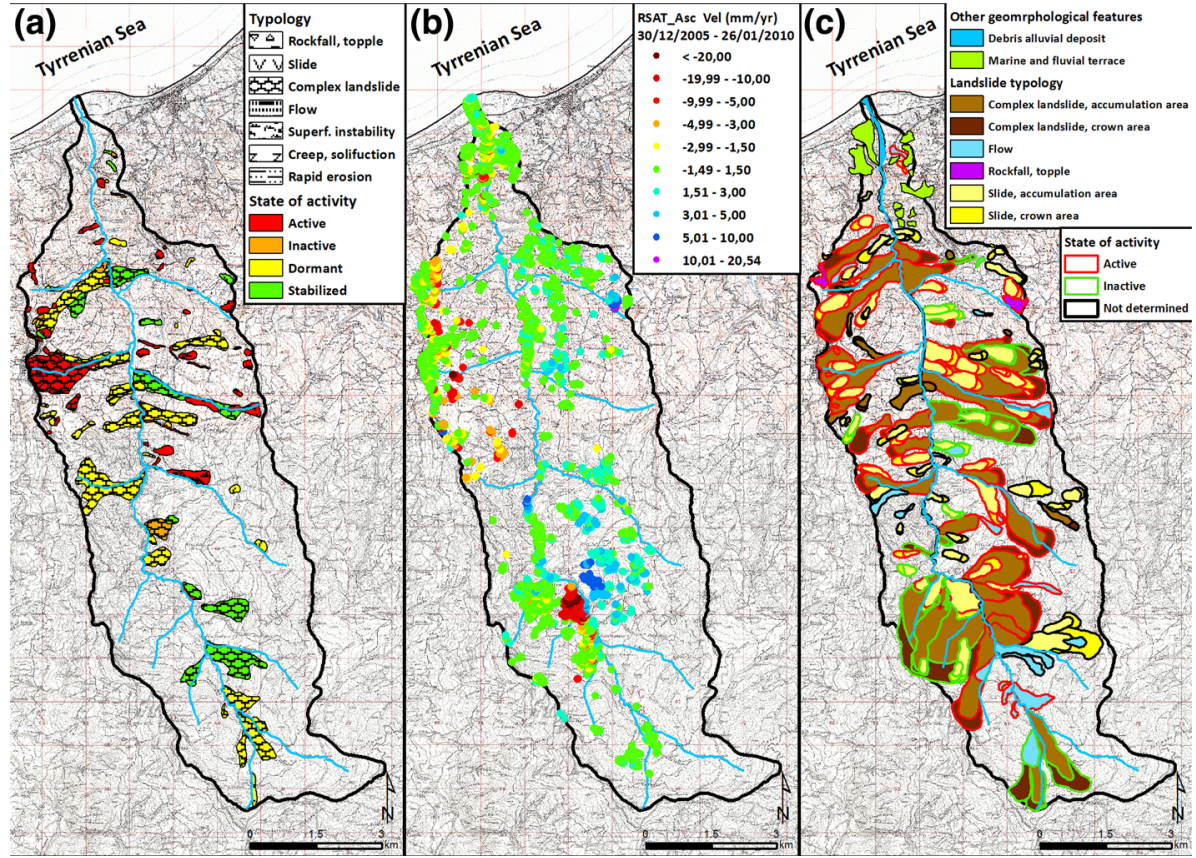

Fig. 2 Updating of the landslide inventory map (LIM) for the Inganno creek. a Pre-existing LSI map; b Radarsat-1 velocity map; c updated LSI 
occurred in 1960 when a newly formed scarp developed at $1160 \mathrm{~m}$ a.s.l. and in 1977 with the formation of a new retrogressed upslope scarp at $1400 \mathrm{~m}$ a.s.l. The landslide develops in highly deformed gneisses and micaschists and is interpreted as a compound slide (complex slide with translation-rotational components) that involves slope debris and fractured rocks with a basal failure 60-90 m deep and a shallower slope surface 12-35 m deep generated at the slope deposit/fractured rock interface (Agliardi and Crosta 2015).

Since 1989, a monitoring network composed of ground-based devices was progressively implemented in the landslide area (Agliardi and Crosta 2015). The data obtained from this ground-based network revealed that the Spriana landslide has been slowly but continuously moving since the beginning of the 1990s. The highest cumulative displacements have been measured in the upper portion of the landslide, near the upper scarp. To improve understanding of the landslide kinematics and to compare the obtained results with ground survey information, three satellite SAR data sets acquired in descending geometry and covering the time period from 1992 to 2010 have been analysed (Table 2).

The SAR data were processed with the PSInSAR algorithm, producing a low density of points in the landslide area but with coherence (a measure ranging from 0 to 1 of the goodness of fit of the model to the observations) values greater than 0.65 in all three data sets. The ERS $1 / 2$ data recorded a mean LOS velocity of $-15.4 \mathrm{~mm} /$ year with a peak of $-21.3 \mathrm{~mm} / \mathrm{year}$, as registered by a PS point located near the north-eastern limit of the upper scarp (Fig. 3a). Radarsat-1 data recorded a mean LOS velocity value of $-9.2 \mathrm{~mm} /$ year, with a peak velocity of $-12.3 \mathrm{~mm} /$ year also detected in proximity to the upper scarp (Fig. 3b). Finally, the Envisat data showed a mean LOS deformation rate of $-7.9 \mathrm{~mm} /$ year, with a peak velocity of $-10.5 \mathrm{~mm} /$ year in the same sector as the previous data sets (Fig. 3c). The interferometric results confirmed that the Spriana landslide is an active phenomenon with deformation rates typical of an "extremely slow landslide", as defined by Cruden and Varnes (1996). The recorded deformation velocities show a decrease in landslide movement from the start of satellite monitoring in 1992 until 2010. As reported by certain authors (Longoni et al. 2014; Agliardi and Crosta 2015), since 1977, when a $2 \mathrm{~m}$ cumulative displacement was estimated by field surveys in only 1 year, the landslide has continuously moved with a velocity that gradually decreases and occasional accelerations related to particularly rainy period associated with snow-melt water infiltration.

Unlike the displacement time series of ERS 1/2 and Radarsat-1 (which show a linear trend of deformation), the Envisat time series exhibits a particular bilinear trend with higher negative deformation rates in the last portion of the series, dating back to July 2008 (Fig. 4). Moreover, analysis of this anomaly allowed the discovery that the PS points located in various sectors of the slope have different breakpoint dates and different magnitudes of LOS velocity changes $(\Delta V)$ :

- Landslide toe: July to September 2008, mean $\Delta V=6.2 \mathrm{~mm} /$ year;

- Lower scarp: December 2008 to February 2009, mean $\Delta V=9.2 \mathrm{~mm} /$ year;

- Upper scarp: April to May 2009, mean $\Delta V=10.1 \mathrm{~mm} /$ year.

Table 2 Characteristics of SAR data sets used in characterization of the Spriana landslide

\begin{tabular}{llllllr}
\hline Satellite & Agency & Temporal range & $\begin{array}{l}\text { Number } \\
\text { of images }\end{array}$ & $\begin{array}{l}\text { Standard } \\
\text { deviation }\end{array}$ & $\begin{array}{l}\text { Maximum negative } \\
\text { velocity (mm/year) }\end{array}$ & $\begin{array}{l}\text { PS density } \\
\left(\mathrm{PS} / \mathrm{km}^{2}\right)\end{array}$ \\
\hline ERS1/2 & ESA & $16 / 05 / 92-19 / 12 / 00$ & 81 & \pm 0.53 & -21.3 & 46.4 \\
Radarsat-1 & CSA & $28 / 04 / 03-18 / 06 / 07$ & 56 & \pm 1.19 & -12.3 & 107.4 \\
Envisat & ESA & $23 / 03 / 04-20 / 07 / 10$ & 48 & \pm 0.43 & -10.5 & 20.6 \\
\hline
\end{tabular}




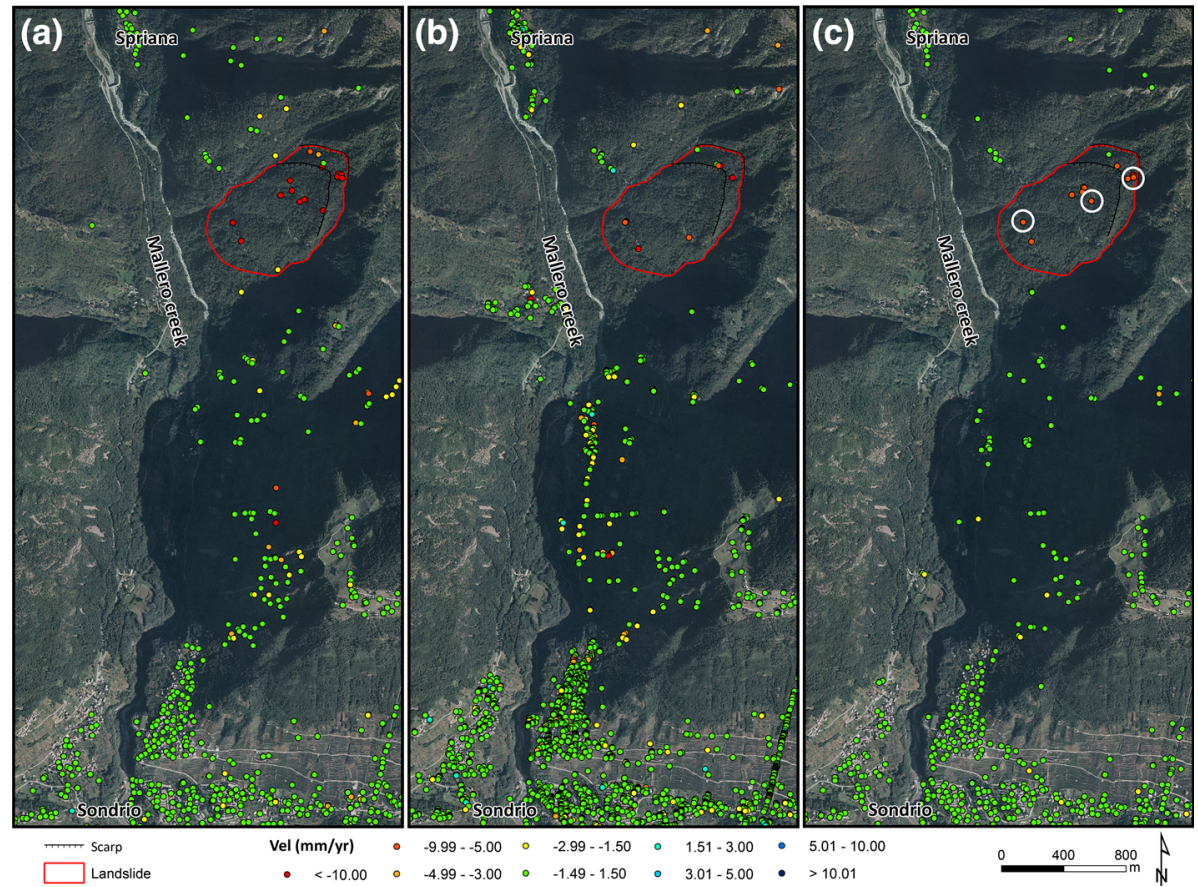

Fig. 3 PSI results for the Spriana landslide. a ERS data set; b Radarsat-1 data set; c Envisat data set

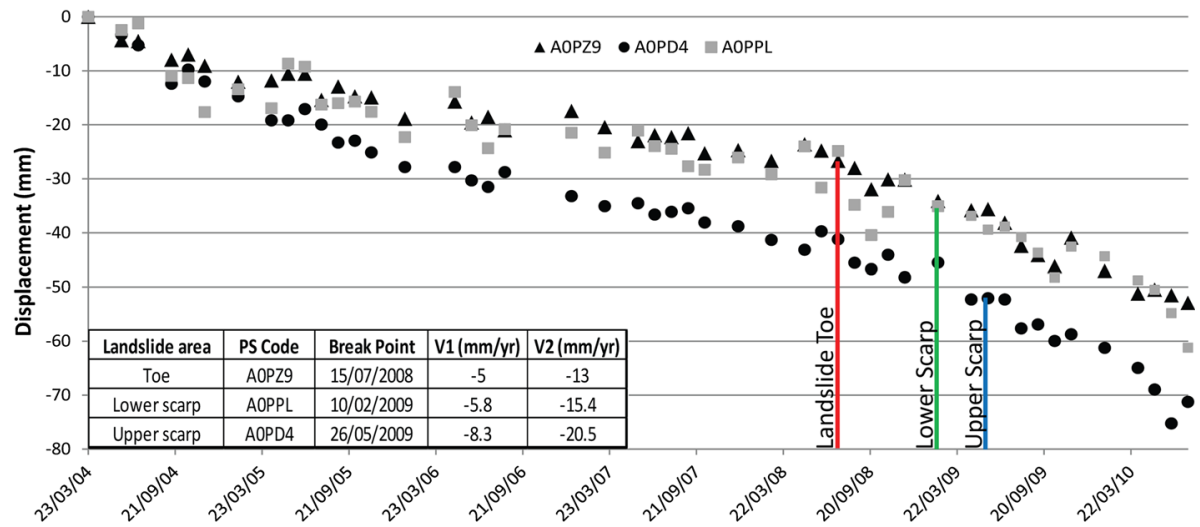

Fig. 4 Envisat deformation time series for different sector of the Spriana landslide

The interferometric results have also been used to define the extent of the landslide and the state of its activity, information that together with the geological and geotechnical data has aided into defining two possible risk scenarios for the Spriana landslide. The first scenario is represented by the activation of a sliding surface $25 \mathrm{~m}$ deep developed in the slope deposits/fractured rocks interface and that involves an estimated volume of $17 \mathrm{Mm}^{3}$. The second scenario is represented by the activation of a sliding surface $80 \mathrm{~m}$ deep that 
involves both slope deposits and fractured rocks and generates an estimated landslide volume of $57 \mathrm{Mm}^{3}$. In both risk scenarios, the formation of a landslide dam in the Mallero River is expected. The possible failure of this newly formed dam could represent a high risk for the city of Sondrio, located at the valley outlet of the Mallero creek (Fig. 3). Using the volume $\left(\mathrm{Vd}\right.$ in $\left.\mathrm{m}^{3}\right)$ of the landslide dam and the basin drainage area $\left(\mathrm{Ab}\right.$ in $\left.\mathrm{km}^{2}\right)$ computed upstream from the dammed section catchment area, it is possible to calculate the blockage index (BI), which is defined as the natural logarithm of the ratio between $\mathrm{Vd}$ and $\mathrm{Ab}$ (Ermini and Casagli 2003). A stable dam is defined if BI is equal to or greater than 5, with an "uncertainty zone" between $\mathrm{BI}=4$ and $\mathrm{BI}=5$. An unstable dam is defined for a $\mathrm{BI}$ ranging from 3 to 4 , whereas a dam is not noted if the $\mathrm{BI}$ is less than 3 . In this case study, the values obtained for the two risk scenarios are:

- $\mathrm{BI}=4.77$ for the first scenario. This value falls near the upper limit of the uncertain domain, meaning that the landslide dam tends towards stability;

- $\mathrm{BI}=5.3$ for the second scenario. This value falls in the stability domain.

In conclusion, satellite monitoring of the Spriana landslide shows that the slope has been slowly but constantly moving during the investigated period, with deformation trends that appear to decrease from 1992 to 2010. This fact is in agreement with the information obtained from inclinometers and extensometers. However, it is interesting to note that an acceleration in the PS velocities registered in the last portion of the Envisat acquisition period has been observed, with a starting point and magnitude that differ from those of the various landslide sectors. Moreover, analysis of the two possible risk scenarios related to the formation of a landslide dam in the Mallero creek has been performed. The results show that a newly formed landslide dam is expected to be stable and is independent of the slope debris volume.

\section{Prevision of landslide risk}

The prevision phase aims to identify areas where landslides are more likely to occur and includes all activities necessary to forecast potential ground deformation scenarios. At the basin/regional scale, due to wide coverage and the ability to retrieve dense ground movement measurements, satellite InSAR can be integrated with susceptibility maps to better define the landslide-prone areas. At the scale of a single landslide event, analysis of long temporal series (longer than 20 years in the best case) can support the identification of anomalous trends in the deformation pattern. This observation allows detection of the most important expected phenomena and consequent effects to suitably manage monitoring and early-warning systems. The likelihood of spatial and temporal occurrence of ground movements, and therefore mitigation of risk, is an essential element in the disaster management cycle.

\subsection{Basin scale: integration of SAR data within susceptibility maps-The Nebrodi range (Sicily Region) case study}

Among several aspects that must be considered in landslide risk assessment and management, the predicted probability of a landslide (and consequently, the vulnerability of and risk to property and people) can be improved using satellite InSAR data. Landslide susceptibility maps (LSMs) are one of the most frequently used tools for prediction of the 
probability of landslide occurrence because they represent the likelihood of a landslide occurring in a specific area based on local terrain factors such as geological, topographical and environmental conditions (Brabb 1984; Guzzetti et al. 2006). LSMs are essential for effective planning activities and land-use management to support decision makers in coping with the existing urban fabric and infrastructural networks and planning their future growth. Several approaches have been proposed to produce accurate LSMs. For example, statistical and landslide inventory-based probabilistic techniques can be used (Carrara et al. 1995; Guzzetti et al. 1999, 2006). To produce accurate and reliable LSMs that can be profitably used in landscape management, it is necessary to reduce misclassification errors as much as possible, especially for urban areas. This problem is especially relevant for landslide susceptibility analysis, and two different groups of errors can affect susceptibility models (Frattini et al. 2010):

- Type I error (false positive): terrains not affected by landslides are classified as unstable;

- Type II error (false negative): terrains affected by ground deformation are classified as stable and incorrectly used without restrictions. Underestimation of the possible losses of at-risk elements that could be involved in a landslide event must be avoided.

Proper landslide risk management requires a reduction in both type of errors, but errors of type II are worse in terms of social and economic losses than errors of type I. PSInSAR data can be used to reduce the number of type II errors related to slow and extremely slowmoving landslides. The combination of LSM and the PSInSAR data can be used to refine the degree of landslide susceptibility in areas affected by ground movements, reduce the number of false negatives and increase the reliability of a landslide susceptibility map. This approach cannot be used to correct type I errors. Following the methodology described in Ciampalini et al. (2016), the integration procedure is performed by increasing the susceptibility degree of those cells characterized by ground deformations highlighted by the PSInSAR data. The proposed approach relies on the use of two data sets acquired in ascending and descending geometries and re-projecting the PS velocity measured along the LOS into a new velocity along the slope $\left(\mathrm{V}_{\text {slope }}\right.$. The integration of the LSM and the $\mathrm{V}_{\text {slope }}$ map was performed using an empirical contingency matrix, which considers the average $\mathrm{V}_{\text {slope }}$ module and the susceptibility degree obtained from the random forests algorithm. This approach was tested in the $1230 \mathrm{~km}^{2}$ wide Nebrodi Mountain range (Sicily Region), which was hit by several exceptional rainfall events between autumn 2009 and winter 2010 (Ciampalini et al. 2015). With respect to the LSM obtained by applying the random forest algorithm (Fig. 5a), the updated LSM (Fig. 5b) shows a decrease in the percentage of the low susceptibility class. In particular, in the updated map, the class "low to null susceptibility" includes $42.06 \%$ ( $45.61 \%$ before correction) of the total number of cells, the class "moderate susceptibility" is $31.98 \%$ ( $30.51 \%$ before correction), class "high susceptibility" is $21.47 \%$ (20.62\% before correction) and class 4 is $4.49 \%$ ( $3.26 \%$ before correction).

The performance of the model of the Nebrodi area was evaluated by conducting receiver operating characteristic (ROC) analysis over the entire landslide database. The area under the ROC curve (AUC) can be used as a metric to assess the overall quality of a model, i.e., the larger the area, the better the performance of the model. One ROC curve is better than another if it is closer to the upper left corner. The AUC value of 0.73 highlights a fair result for the LSMs of the Nebrodi area. Following refinement with PSI data, the AUC increases to 0.81 , highlighting a more reliable result.

The combination of an LSM obtained via the classic approach and the PSInSAR data leads to an improvement in the susceptibility ranking of a portion of the entire study area 
(a)

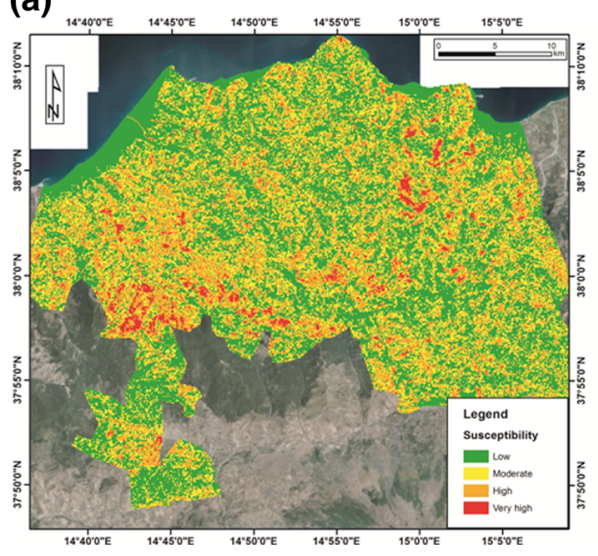

(b)

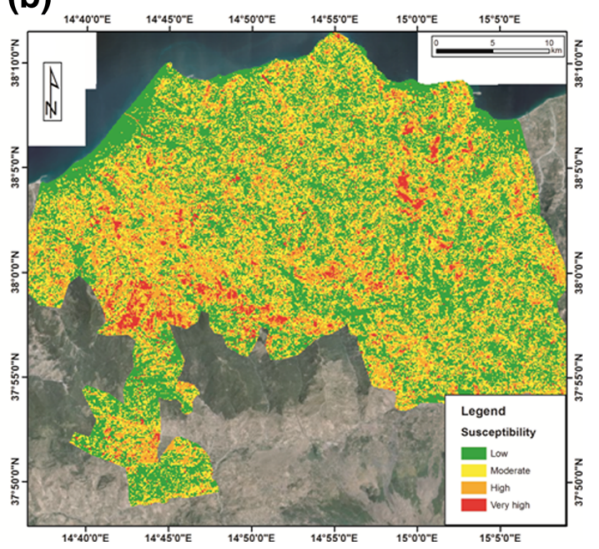

Fig. 5 Comparison of a LSM obtained by applying the Random Forest Algorithm and $\mathbf{b}$ new LSM after applying the correction matrix based on satellite SAR data

(approximately a quarter). The main limitation of the proposed methodology is related to the intrinsic limitations of the SAR technique (vegetation cover, foreshortening, layover, etc.), which reduce the percentage of the area that can be refined. In contrast, the main advantage is represented by the ability to update the LSM in urbanized areas affected by hillslope processes where the elements at risk (buildings, people and infrastructure) are present. In these areas, a reliable LSM is a fundamental tool for hazard and risk management. PSInSAR data are normally used to improve the accuracy of the LIM, which in turn is used to perform the LSM. This update is often time-consuming because the state of activity and the boundaries of each landslide must be visually checked based on the PS distribution and velocity. A combined use of the updated LSM and the ground deformation velocity map could be highly useful in forecasting slow-moving landslides in a specific area, improving prediction capability and supporting decision making authorities in production of reliable LSMs, especially for urbanized areas.

\subsection{Local scale: deformation time series analysis-The San Leo (Emilia Romagna Region) case study}

With respect to conventional single-pair interferometry, a great advantage of multi-interferogram approaches is their ability to generate time series of ground deformations for individual elementary reflectors (i.e. PS), assuming linear (e.g. Ferretti et al. 2001) or nonlinear (e.g. Ferretti et al. 2011) deformation models to retrieve different components of the displacement. The accuracy of the single measurement corresponding to a single SAR acquisition ranges from 1 to $3 \mathrm{~mm}$ (Colesanti et al. 2003). The time series of deformation represents the most advanced PSI product, creating the deformation history, highlighting any changes that have occurred during the monitoring period (Notti et al. 2011) and allowing comparison of the displacement with other source information (Tomás et al. 2015). This potential has been exploited to retrieve advanced information on the deformation affecting the historical town of San Leo (Emilia Romagna Region) and to identify the presence of precursor movements prior to the major event that occurred on 27 February 2014. San Leo is a small medieval town with a famous fortress built on a hilltop constituted by a quadrangular-shaped rock plate approximately $0.3 \mathrm{~km}^{2}$ wide and bordered by sub- 
vertical and overhanging cliffs up to $100 \mathrm{~m}$ in height. The plate consists of limestone and sandstone overlying clays with marly and limy sandstones. The geological settings of the site affect its geomorphological features and the related instability events. The soft clayey bedrock is strongly affected by erosive phenomena, causing instability processes and undermining of the overlying brittle rock plate. On 27 February 2014, the north-eastern sector of the rock massif collapsed, causing a rock fall of approximately $0.3 \mathrm{Mm}^{3}$ (Borgatti et al. 2015). The event caused a retreat of the cliff edge. Fortunately, no fatalities or injuries occurred, but nevertheless, certain buildings located in the town's northern sector were evacuated as a precautionary measure. Following the described event, monitoring activity of the ground displacement was initiated (Frodella et al. 2016). To characterize the pre-event displacement, two sets of archival satellite COSMO-SkyMed images were acquired and processed using the SqueeSAR approach (Ferretti et al. 2011) (Table 3).

SqueeSAR analysis using the ascending data set highlighted the ground deformation phenomena as mainly located in areas corresponding to the soft clayey bedrock at the foot of the north-western, northern and eastern rock-plate-bordering wall sectors (Fig. 6a), corresponding to slow-moving flows. The ascending data set indicates an overall stability for most of the rock plate (i.e. the PS are characterized by velocities included in the stability threshold). Nevertheless, the presence of an area located in the northern sector of the village affected by active deformation (on the order of 3-5 $\mathrm{mm} /$ year) can be identified. It is worth remarking that this specific sector of the rock plate was the origin of the first phase of the rockfall event (Fig. 6b). To identify the presence of ground acceleration and any potential changes occurring during the monitoring period, thus contributing to the identification of precursor movements prior to major events, two different "post-processing" approaches (Berti et al. 2013; Cigna et al. 2012a, b) were applied to the time series of the ascending data set. Berti et al. (2013) developed a tool for automatic classification of PSI time series based on a conditional sequence of statistical tests. This automatic analysis overcomes limits related to visual classification of PSI time series, which is time-consuming, and cannot be performed systematically for large data sets. Such a tool classifies the time series into six distinctive pre-defined target trends (which describe different styles of ground deformation), such as uncorrelated (Type 0), linear (Type 1), quadratic (Type 2), bilinear (Type 3) and discontinuous with constant (Type 4) and variable velocities (Type 5), and offers additional parameters, such as the break date (date identifying the trend change). The results of application of this automatic classification to the ascending data set of San Leo are shown in Fig. 6c. The majority of the time series is classified as "uncorrelated" $(74.1 \%)$ or "linear" $(19.9 \%)$, which means that most of the PSs are stable (Type 0 denotes fluctuations of displacements near zero) or characterized by movements at constant rate or without significant variation of velocity, i.e., the slowmoving earth flows at the foot of the north and east sectors of the cliff. Nonlinear types (from 2 to 5) are a small minority, accounting for only $6 \%$ and mostly consisting of bilinear trends (Type 3), which characterizes a time series segmented into two linear tracts of different velocities separated by a breakpoint. An interesting cluster of targets with a

Table 3 Characteristics of SAR data sets used in analysis of the San Leo hilltop during the pre-event phase

\begin{tabular}{lllllll}
\hline Satellite & Agency & Band & Geometry & Revisiting time (day) & Temporal range & No. scenes \\
\hline CSK & ASI & $\mathrm{X}$ & Ascending & 16 & $09 / 05 / 2011-26 / 02 / 2014$ & 39 \\
CSK & ASI & $\mathrm{X}$ & Descending & 16 & $13 / 03 / 2010-06 / 01 / 2014$ & 35 \\
\hline
\end{tabular}




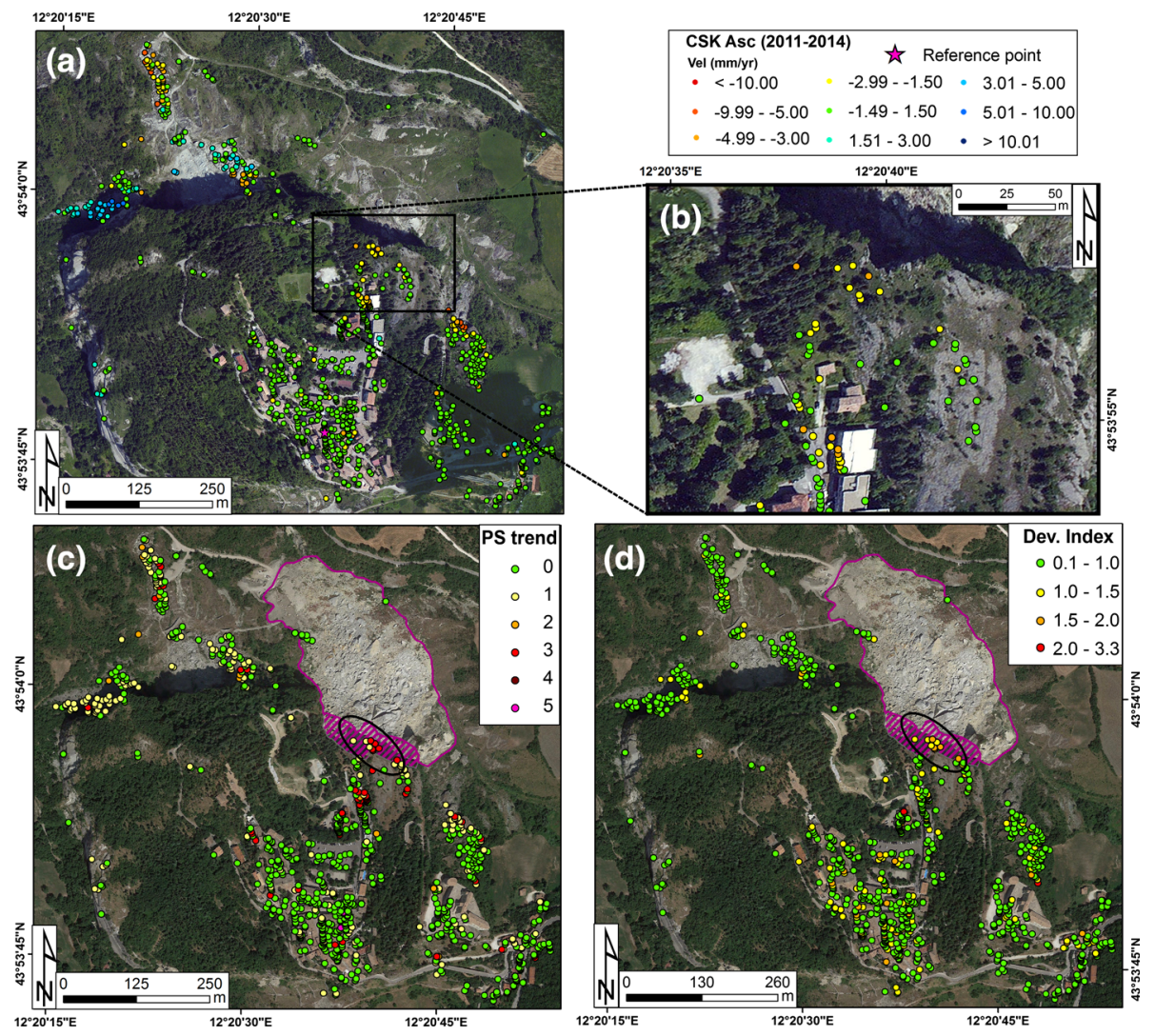

Fig. 6 PSI results for the San Leo rock plate. a COSMO-SkyMed velocity maps; b close-up of the northeast border; c PS trend according to Berti et al. (2013) displayed on post-event orthophotograph; d PS deviation index according to Cigna et al. (2012a, b) displayed on post-event orthophotograph. The violetdashed area maps the sector of the rock plate fall on 27 February 2014. The violet line represents the accumulation area

bilinear trend is located in the northern sector of the rock plate. It worth remarking that this sector was the origin of the first phase of the rockfall event (black oval in Fig. 6c). These points are characterized by strong bi-linearity, and the break date $(\mathrm{Tb})$ of the time series on 21 October 2013 can be identified. The change in the general trend recorded from this date is attributed to progressive ground acceleration, a potential precursor of the major landslide failure of 27 February 2014.

Once the break date is known, the deviation index (DI1) developed by Cigna et al. (2012a, b) was applied to quantify the trend deviations within the time series (TS). This index is able to quantify the deviation recorded after $\mathrm{Tb}$ with respect to its prediction based on the linear regression of the TS records prior to $\mathrm{Tb}$. The results of application of this classification to the ascending data set of San Leo are shown in Fig. 6d. The resulting values of DI1 range between +0.1 and +3.3 , with more than $83 \%$ of the targets characterized by DI1 values less than +1.0 (green targets in Fig. 6d), also including (as expected) the points within the landslides at the foot of the northern sector of the cliff. Few PSs show high deviation indexes, demonstrating the occurrence of strong deviations with respect to the history from previous years. Additionally, in this case, the most interesting 
cluster of targets (black oval in Fig. 6d) with high values of DI1 is located in the northern sector of the rock plate, the origin of the rockfall event of February 2014. In this case, the PSs are characterized by DI1 values between +1.0 and +2.0 , and the time series of these PSs showed up to 1-2 cm of progressive LOS movements accumulating in four months before the event. These observed movements likely indicate an acceleration of ground deformation that preceded the failure of February 2014.

\section{Landslide emergency response: The Montescaglioso (Basilicata Region) case study}

Protection of life and property during disasters is the goal of the response phase. More specifically, this phase includes all activities necessary to collect information on the disrupting event, surveillance of the event and the definition of emergency plans to deliver an efficient response to calamities. This phase involves timely evacuation of the affected site, evaluation of building damage and safety, implementation of effective monitoring systems and adoption of preliminary stabilization measures. In this framework, remote sensing is an effective tool used to obtain a broad view of the disaster events occurring in a specific area and to assess the extent (magnitude, location) of ongoing surface deformation, especially where access to the landslide area might be too dangerous to perform field mapping due to the magnitude of the ground displacement and the velocity of the failure.

The potential of satellite SAR data has been exploited for rapid mapping of the deformation field induced by the landslide that occurred on 3 December 2013 in the village of Montescaglioso (Basilicata Region). The landslide, which was triggered by $56 \mathrm{~h}$ of continuous rainfall, can be included within the "rapid" class $(1.8 \mathrm{~m} / \mathrm{h} \leq$ vel $<3 \mathrm{~m} / \mathrm{min})$ of the Cruden and Varnes (1996) classification scheme because the movement occurred within a period of $20 \mathrm{~min}$ and resulted in remarkable geomorphological effects with a maximum displacement of more than 15 metres corresponding to a velocity of $0.75 \mathrm{~m} / \mathrm{min}$. The landslide disrupted several sectors of the road networks, rendering them unusable, caused severe damage to private buildings and commercial and artisan activities and resulted in the collapse of a supermarket. Luckily, no fatalities occurred, but for security reasons, 10 houses were evacuated after the landslide. The movement affected an area of approximately $0.4 \mathrm{~km}^{2}$, resulting in a $1.5-\mathrm{km}$-long main scarp in a series of trenches (up to 2-3 m wide), scarps and counterscarps tens of metres in length and with heights up to 8-10 m. Immediately after the event, following the official request by the DPC to ASI, the Italian SAR constellation of X-band satellites COSMO-SkyMed (CSK) was tasked to acquire Stripmap images (ground resolution of $3 \times 3 \mathrm{~m}^{2}$ ) with an effective revisiting time of 8 days in addition to the availability of two data sets of archive images acquired along ascending and descending geometries. Table 4 presents the timing of the different activities performed after the landslide occurrence.

The high deformation rates of the landslide caused the conventional DInSAR analysis to fail. As mentioned previously, the application of amplitude-based speckle-tracking analysis to SAR data pairs before and after the event reduces the spatial decorrelation, offering a quantitative assessment of the extent and the amount of ground displacement associated with the event (Fig. 7). The retrieved ground deformation has dominant SW components, with a minor south component close to its right limit. The deformation values range between 8 and $12 \mathrm{~m}$ for large sectors of the landslide. Surface deformation generally increases moving towards the left limit of the landslide, with values up to $18-20 \mathrm{~m}$. The 
morphological evidence surveyed and the deformation field indicates a main translationaltype movement. Two smaller landslides have been detected in the upper portion of the slope, with a main SE movement direction. The first landslide (ellipse 1 in Fig. 7) likely occurred as retrogressive movements of the landslide, and the second smaller one (ellipse 2 in Fig. 7) affected the westernmost limit of the scarp of the main landslide. Speckletracking results were successfully compared with in situ investigations primarily devoted to surveying the landslide boundary and the main scarp via GPS device and field analysis.

According to Boccardo (2013), during the response and recovery phase of the emergency management cycle, rapid mapping of natural and/or human-made disasters is a key point for support by Civil Protection and a standard practice in operational service. In this framework, the immediate availability of satellite images and the growing ability of the current techniques to map a wide range of deformative processes play fundamental roles.

\section{Post-landslide emergency: The Cavallerizzo di Cerzeto (Calabria Region) case study}

The post-emergency phase following a catastrophic event includes all of the recovery activities necessary to restore ordinary living conditions. This phase addresses rehabilitation, recovery and restoration of the pre-disaster environment. During the post-emergency phase, the main aim of Civil Protection activities is to guarantee permanent reduction in the risk of landslide reactivation and restoration of basic social functions. In this framework, the contribution of satellite SAR is twofold: assessment of residual movements after the occurrence of a slope failure and the identification of safe areas for relocation with the support of geomorphological analysis.

The activities performed following the landslide that affected the village of Cavallerizzo di Cerzeto (Calabria Region) were based on the valuable information delivered by satellite SAR interferometry, which effectively supported the Civil Protection authorities in emergency management and response. On 7 March 2005, due to heavy and continual rainfall (645 $\mathrm{mm}$ of cumulated rainfall in 90 days), a large complex debris slide/earth flow occurred, affecting and destroying a significant portion of the village of Cavallerizzo. The landslide occurred in an area with a long history of slope instabilities, and the 2005 event is only the most recent major episode in a long-lasting deformation process. Precursory movements and anomalous displacement were recorded at the end of February 2005 (for details, see Iovine et al. 2006), allowing timely warning to the population. No causalities occurred, but the village suffered severe damage. Thirty buildings in the southernmost

Table 4 Timing of the activities performed after the landslide occurrence

\begin{tabular}{ll}
\hline Day & Type of activity \\
\hline $03 / 12 / 2013$ & Landslide occurrence \\
$12 / 12 / 2013$ & Official request of the DFC to ASI \\
$12 / 12 / 2013$ & Acquisition of the first post-event image along descending orbit \\
$18 / 12 / 2013$ & Acquisition of the first post-event image along ascending orbit \\
$19 / 12 / 2013$ & Availability of full SAR images data set (early morning) \\
$19 / 12 / 2013$ & Begin of SAR processing of asc and desc data set (both Advanced InSAR and \\
& speckle tracking) \\
$23 / 15 / 2013$ & Delivery of the results to DPC \\
\hline
\end{tabular}




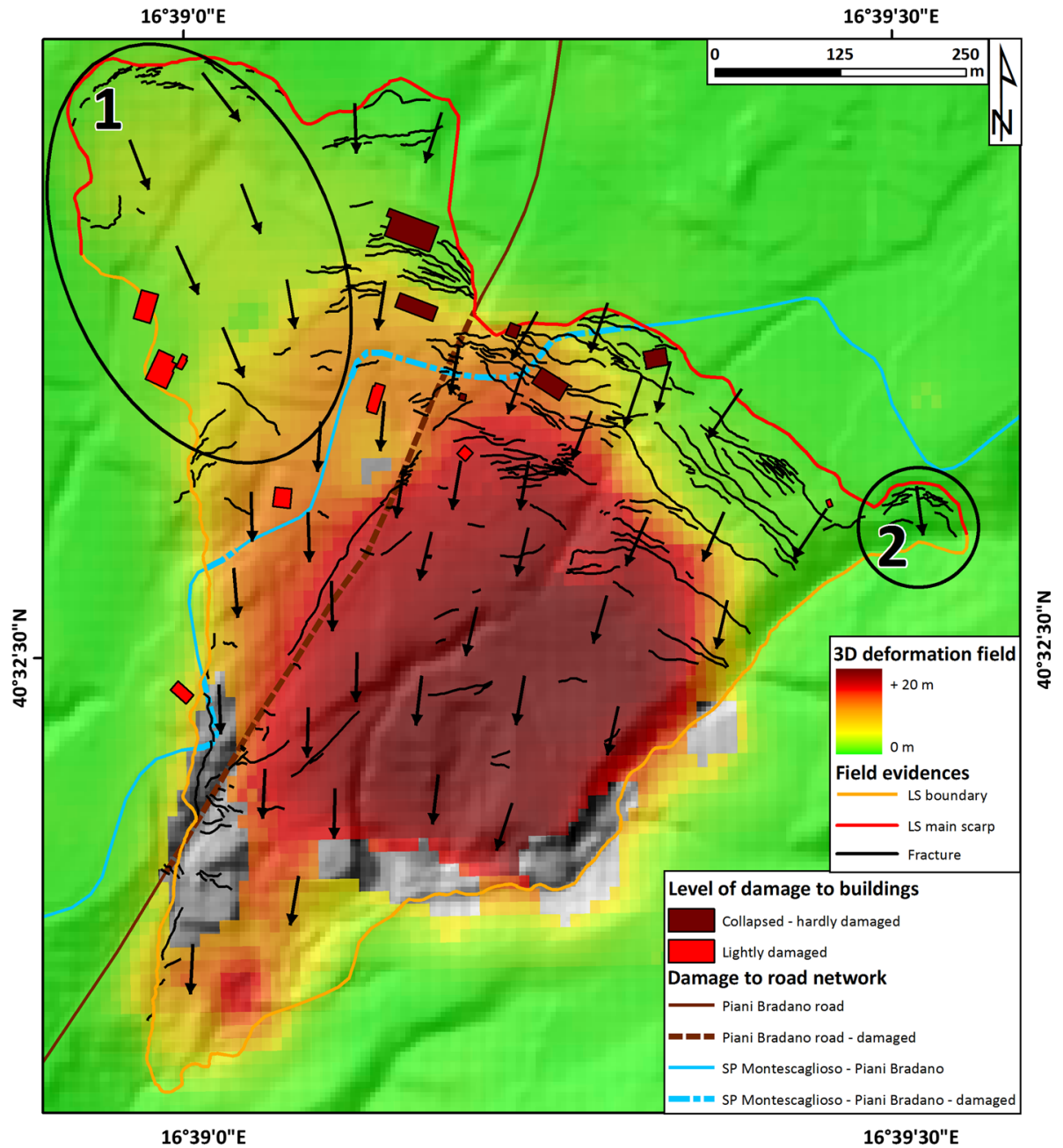

Fig. 7 Map of surface deformation of the Montescaglioso landslide on 3 December 2013 obtained from speckle-tracking analysis. The arrows show the main direction of movement

portion of the village were severely damaged or destroyed by the landslide activation, and many buildings were subjected to partial or moderate damage. A large sector of the main road connecting Cavallerizzo to Cerzeto and to the other village of the municipality was disrupted. More than 300 inhabitants were evacuated.

Following the initial landslide movements, monitoring of the area was initiated using satellite SAR data processed with multi-interferogram techniques. The monitoring activity was focused on the following aspects: (1) study of the historical evolution of the landslide and assessment of the residual movements involving the residential area and (2) identification of areas not affected by ground motion and not involved in hydrogeological instability processes that were suitable for building a new town. Immediately after the event, a series of PSInSAR processing operations were performed using ascending and descending images collected by ERS (1992-2001) and Radarsat-1 (2003-2005) satellites, 
which offered information on the high landslide deformation rate and produced evidence of other older unstable areas in addition to those affected by the March event (Canuti et al. 2007). Considering the described scenario, either the landslide had to be quickly stabilized or the affected village had to be relocated. InSAR data on ground measurements coupled with field survey and geological and geomorphological investigations confirmed the extension, the critical conditions of the area and the persistence of high landslide risk related to high activity of the landslide. The performed investigations also showed that the slope could not be stabilized at a reasonable cost to the community, and therefore, to avoid future disaster, Civil Protection authorities decided to permanently evacuate the entire village and relocate people to a safer area. Furthermore, InSAR processing (Fig. 8) was performed by exploiting Radarsat-1 (2004-2010) and Radarsat 1\&2 (2010-2015) to retrieve updated information on the ground deformation of the wider area of Cavallerizzo. For brevity, only the analysis of the latter Radarsat data sets covering the period 2004-2015 is presented in this paper (Table 5).

The SqueeSAR analysis of the first data set (2004-2010) highlights the significant displacement involving the entire village of Cavallerizzo di Cerzeto (Fig. 8 on the left). Interferometric data on the area of Pianette, selected as the relocation site (blue line of Fig. 8), are not shown because during the acquisition interval time, the site was characterized by a strong decorrelation time related to the construction of new buildings. In the hamlet of Cavallerizzo, 283 measurement points with LOS deformation rates ranging between -3.03 and $-19.17 \mathrm{~mm} /$ year have been identified, highlighting the presence of active movements. The highest values were recorded in the south-west portion of the village close to the landslide scarp. Considering the acquisition geometry (ascending) and the slope orientation (SE facing slope), the deformation data are consistent with the occurrence of slope movements affecting the village of Cavallerizzo.

The stitched SqueeSAR analysis of the second data set (2010-2015), which includes Radarsat-1 and Radarsat-2 images, confirmed the persistency of active movements affecting the entire Cavallerizzo village (Fig. 8 on the right). In the hamlet of Cavallerizzo, 149 measurement points with LOS deformation rates ranging between -1.89 and $-24.3 \mathrm{~mm} /$ year have been identified. The deformation rates recorded in this time interval in the area of Cavallerizzo are comparable to those detected in the previous period (2004-2010). Nonetheless, areas where the deformation rates are slightly varied can be recognized in the upper portion of the village (the mean LOS velocity increased from 8.5 to $9.5 \mathrm{~mm} /$ year) and in the south-western portion (the mean LOS velocity decreased from 11.5 to $6.5 \mathrm{~mm} /$ year). The most striking difference between the two data sets is the appearance of measurement points in the second data set for the area of Pianette because during the period 2010-2015, the site was no longer subject to decorrelation. This zone is characterized by negligible LOS deformation rates ranging between -1.5 and $+1.5 \mathrm{~mm} /$ year (i.e. within the interval of the interferometric technique sensitivity), reflecting relatively stable ground conditions. Selected isolated points with low LOS deformation rates (between 2 and $4 \mathrm{~mm} /$ year) are likely related to soil consolidation due to recent construction.

These two data sets show the evolution of displacement before (2004-2010) and after (2010-2015) the event, highlighting how the movements still affect the village of Cavallerizzo di Cerzeto and how they persisted several years after the trigger, thus confirming the ground stability of the site selected for relocation. SqueeSAR data created a complete view of the post-event deformation processes affecting the study area, and the presented results represent an important tool in the post-emergency phase, allowing 

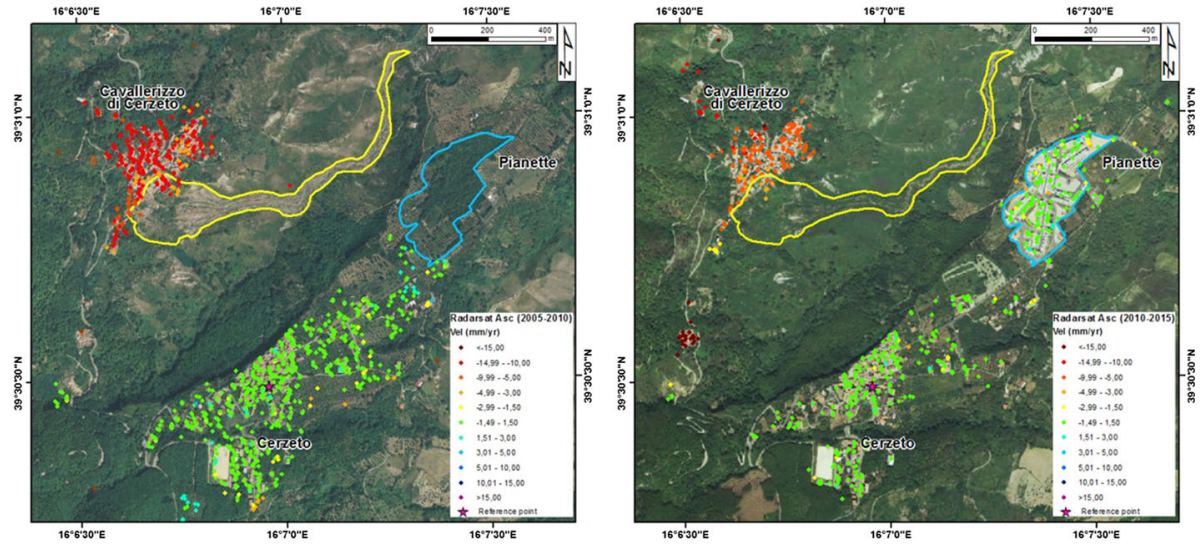

Fig. 8 PS ground deformation rate maps for the wider area of Cerzeto. Left Radarsat-1 (2004-2010) data displayed on orthophotograph acquired on 19 August 2006; Right Radarsat-1\&2 (2010-2015) data displayed on orthophotograph acquired on 12 May 2012. The yellow line represents the 2005 landslide boundary, and the blue line delimits the relocation area

Table 5 Characteristics of SAR data sets used in analysis of ground deformation in the wider area of Cavallerizzo

\begin{tabular}{lllllll}
\hline Satellite & Agency & Band & Geometry & $\begin{array}{l}\text { Revisiting } \\
\text { time (day) }\end{array}$ & Temporal range & No. scenes \\
\hline Radarsat-1 & CSA & C & Ascending & 24 & $07 / 11 / 04-10 / 10 / 10$ & 56 RSAT1 \\
Radarsat-1\&2 & CSA & C & Ascending & 24 & $16 / 01 / 10-23 / 09 / 15$ & 34 RSAT1 + 44 RSAT2
\end{tabular}

detection of stable areas and verification of the persistence of ground deformation that affects the unstable zones identified during the emergency phase.

\section{Discussion}

This work presented the use of satellite SAR images processed in different manners to exploit both the phase and the amplitude of radar signals for landslide investigations in a Civil Protection framework. The examples included in this paper demonstrated how the SAR-based products are able to deliver valuable results during the different phases of landslide risk management at both the regional and local scale. The wide area coverage coupled with the centimetre to millimetre accuracy of the InSAR approaches (both conventional and advanced) have been widely recognized as a reliable tool for compilation/ updating of landslide inventory maps. Integration of InSAR data and conventional investigation methods (e.g. stereoscopic analysis of aerial photographs and field surveys) can be used to better define the landslide boundaries and their states of activity to highlight the areas affected by ground displacements located outside the boundaries of the originally mapped landslides and to detect ground deformation phenomena not previously mapped. The ability to retrieve ground movement measurements in urban and peri-urban areas, if properly handled, makes InSAR ideally suited for refinement of landslide susceptibility maps (usually compiled at the basin/regional scale), especially for those areas where slope instability 
threatens anthropic structures. An accurate landslide susceptibility map is a basic step required to obtain other more advanced products such as hazard and risk maps. At a more local scale, characterization of a single landslide can be performed by exploiting the time series of deformation. By creating the deformation history over the observed period, the time series facilitates geological interpretation of a landslide and allows for better understanding of the landslide geometry and kinematics, highlighting changes in deformation rates, and supporting the identification of precursor movements prior to major events.

Immediately after a major landslide, rapid mapping of the area affected by the event and measurements of the associated deformation field are of paramount interest for identifying at-risk elements (e.g. buildings, road networks and infrastructure in general) that are endangered by mass wasting, designing monitoring networks and implementing earlywarning systems. In this framework, the enhanced capabilities of X-band satellites in terms of spatial and temporal resolution coupled with an unprecedented flexibility of use and timeliness of delivery offer new opportunities during emergency and post-emergency phases associated with landslides.

SAR-based post-event deformation maps can contribute to assessment of the effectiveness of remedial measures, management of the residual risk associated with the persistence of ground movements that potentially lead to further failures, improvement in analyses and investigations performed immediately after the event and provision of useful data to verify the stability conditions of areas selected for relocation.

The ability to measure notably slow ground movements, on the order of few millimetres per year (which in certain cases is too slight to be noted in conventional methods or by field surveys), results in effective support to landslide hazard prevention activities planned during the pre-crisis periods (i.e. in deferred time) by Civil Protection authorities. However, to date, the most serious gap in the extensive use of satellite SAR information as a (near) real-time monitoring tool is represented by the reduced revisit capacity of the current SAR missions. A further critical issue for the use of remotely sensed data in the prevision phase is the general lack of SAR images acquired on a regular basis that could guarantee reliable identification of an anomalous trend in the deformation time series and the existence of movements before a catastrophic collapse.

We hope that in future, the increased number of available satellite data sources characterized by short revisiting times and high spatial resolution will deliver key information layers for decision support systems and early-warning programmes on a regional and national scale. In particular, the launch of the Sentinel-1 constellation, with a systematic revisiting time of 6 days, will ensure C-band SAR data continuity with the ERS and Envisat missions and deliver consistent archives of acquisition dating back to 1992. Long archives will create an unprecedented retrospective view of a specific area of interest, allowing for the definition of deformation models. Additionally, the availability of regular updates in the time series of deformation will contribute to prompt identification of changes in the deformation pattern and precursor movements that are attributable to major events (such as accelerations recorded before landslide failures).

\section{Conclusions}

Since the late 1990s, important advancements have been reported in the exploitation of SAR data and associated processing chains to detect, map, monitor and model individual and multiple ground deformations. In the last 20 years, in particular, an increasing number 
of innovative research and technological achievements have been reported in Earth Observation with SAR sensors. These advances led to the development of techniques and applications aimed at demonstrating the applicability of images captured by satellite SAR sensors to landslide investigations and the progressive adoption of SAR technology in the operational phases of landslide risk management. Currently, interferometric approaches are widely consolidated for analysis of slow-moving slope deformations in a variety of environments, and exploitation of the amplitude data in SAR images is a somewhat natural complement for rapid-moving landslides. Six case studies in Italy were presented and analysed in this work for the purpose of showing the advantages and drawbacks of interferometric data during the main activities that must be performed during different phases of the risk management strategy (i.e. prevention, prevision, emergency response and post-emergency). In all phases, different benefits can be derived from the use of SARbased measurements, which were demonstrated to be effective in the field of landslide analysis. The path forward for the full use of satellite SAR images as an operational tool in Civil Protection practices is neither complete nor smooth, especially in the field of monitoring and prevision of slope instability. The critical gaps between user needs and actual answers to these requests and from what is observed to what must be observed to fulfil expectations still remain large. Nevertheless, in the future, the increased number of available satellites characterized by short revisiting time and high spatial resolution will offer key information layers for decision support systems and early-warning programmes on a regional and national scale and will contribute to filling the existing gaps.

Acknowledgements The authors thank the Italian Department of Civil Protection for continuous support during the landslide-related emergencies described above. The authors are also grateful to the Tele-Rilevamento Europa (TRE) staff for conducting all data processing phases.

Open Access This article is distributed under the terms of the Creative Commons Attribution 4.0 International License (http://creativecommons.org/licenses/by/4.0/), which permits unrestricted use, distribution, and reproduction in any medium, provided you give appropriate credit to the original author(s) and the source, provide a link to the Creative Commons license, and indicate if changes were made.

\section{References}

AdB Regione Sicilia (2012) PAI (Piano Stralcio di Bacino per l'Assetto Idrogeologico) http://www.sitr. regione.sicilia.it/pai. Accessed 21 Mar 2016

Agliardi F, Crosta GB (2015) Long-and short-term controls on the Spriana rockslide (Central Alps, Italy). In: Sassa K, Canuti P, Yin Y (eds) Landslide science for a safer geoenvironment. Springer, pp 243-249

Aleotti P, Chowdhury R (1999) Landslide hazard assessment: summary review and new perspectives. Bull Eng Geol Environ 58:21-44

Bardi F, Frodella W, Ciampalini A, Bianchini S, Del Ventisette C, Gigli G, Fanti R, Moretti S, Basile G, Casagli N (2014) Integration between ground based and satellite SAR data in landslide mapping: the San Fratello case study. Geomorphology 223:45-60

Bardi F, Raspini F, Ciampalini A, Kristensen L, Rouyet L, Lauknes TR, Frauenfelder R, Casagli N (2016) Space-borne and ground-based InSAR data integration: the Åknes test site. Remote Sens 8(3):237

Belloni L, Gandolfo M (1997) La frana di Spriana. Geologia tecnica ed ambientale 3:7-36

Berti M, Corsini A, Franceschini S, Iannacone JP (2013) Automated classification of persistent scatterers interferometry time-series. Nat Hazards Earth Syst Sci 13:1945-1958

Bhattacharya A, Mukherjee K, Kuri M, Vöge M, Sharma ML, Arora MK, Bhasin RK (2015) Potential of SAR intensity tracking technique to estimate displacement rate in a landslide-prone area in Haridwar region, India. Nat Hazards 79(3):2101-2121

Bianchini S, Cigna F, Righini G, Proietti C, Casagli N (2012) Landslide hotspot mapping by means of persistent scatterer interferometry. Environ Earth Sci 67:1155-1172 
Boccardo P (2013) New perspectives in emergency mapping. Eur J Remote Sens 46:571-582

Borgatti L, Guerra C, Nesci O, Romeo RW, Veneri F, Landuzzi A, Benedetti G, Marchi G, Lucente CC (2015) The 27 February 2014 San Leo landslide (northern Italy). Landslides 12:387-394

Bovenga F, Wasowski J, Nitti DO, Nutricato R, Chiaradia MT (2012) Using COSMO/SkyMed X-band and ENVISAT C-band SAR interferometry for landslides analysis. Remote Sens Environ 119:272-285

Brabb EE (1984) Innovative approaches to landslide hazard mapping. In: Proceedings 4th international symposium on landslides, Toronto, vol 1, pp 307-324

Canuti P, Casagli N, Ermini L, Fanti R, Farina P (2004) Landslide activity as a geoindicator in Italy: signifcance and new perspectives from remote sensing. Environ Geol 45(7):907-919

Canuti P, Casagli N, Catani F, Falorni G, Farina P (2007) Integration of remote sensing techniques in different stages of landslide response. In: Sassa K, Fukuoka H, Wang F, Wang G (eds) Progress in landslide science. Springer, Heidelberg, pp 251-260

Carrara A, Cardinali M, Guzzetti F, Reichenbach P (1995) GIS technology in mapping landslide hazard. Geographical information systems in assessing natural hazards. Springer, Netherlands, pp 35-175

Ciampalini A, Raspini F, Bianchini S, Frodella W, Bardi F, Lagomarsino D, Di Traglia F, Moretti S, Proietti C, Pagliara P, Onori R, Corazza A, Duro A, Basile G, Casagli N (2015) Remote sensing as tool for development of landslide geodatabase: the case of the Messina province (Italy) geodatabase. Geomorphology 249:103-118

Ciampalini A, Raspini F, Lagomarsino D, Catani F, Casagli F (2016) Landslide susceptibility map refinement by using PSInSAR data. Remote Sens Environ 184:302-315

Cigna F, Del Ventisette C, Liguori V, Casagli N (2011) Advanced radar-interpretation of InSAR time series for mapping and characterization of geological processes. Nat Hazards Earth Syst Sci 11:865-881

Cigna F, Del Ventisette C, Gigli G, Menna D, Agili F, Liguori V, Casagli N (2012a) Ground instability in the old town of Agrigento (Italy) depicted by on-site investigations and persistent scatterers data. Nat Hazards Earth Syst Sci 12:3589-3603

Cigna F, Tapete D, Casagli N (2012b) Semi-automated extraction of deviation indexes (DI) from satellite persistent scatterers time series: tests on sedimentary volcanism and tectonically-induced motions. Nonlinear Process Geophys 19(6):643-655

Cigna F, Bianchini S, Casagli N (2013) How to assess landslide activity and intensity with persistent scatterer interferometry (PSI): the PSI-based matrix approach. Landslides 10(3):267-283

Colesanti C, Ferretti A, Prati C, Rocca F (2003) Monitoring landslides and tectonic motions with the permanent scatterers technique. Eng Geol 68:3-14

Corsini A, Farina P, Antonello G, Barbieri M, Casagli N, Coren F, Guerri L, Ronchetti F, Sterzai P, Tarchi D (2006) Space-borne and ground-based SAR interferometry as tools for landslide hazard management in civil protection. Int J Remote Sens 27(12):2351-2369

Cruden DM, Varnes DJ (1996) Landslide types and processes. In: Turner AK, Schuster RL (eds) Landslides: investigation and mitigation. National Academy Press, Washington DC, pp 36-75

De Zan F (2014) Accuracy of incoherent speckle tracking for circular Gaussian signals. IEEE Geosci Remote Sens Lett 11:264-267

Del Ventisette C, Ciampalini A, Manunta M, Calò F, Paglia L, Ardizzone F, Mondini AC, Reichenbach P, Mateos RM, Bianchini S et al (2013) Exploitation of large archives of ERS and ENVISAT C-band SAR data to characterize ground deformations. Remote Sens 5:3896-3917

Del Ventisette C, Righini G, Moretti S, Casagli N (2014) Multitemporal landslides inventory map updating using spaceborne SAR analysis. Int J Appl Earth Obs Geoinform 30:238-246

Dilley M, Chen RS, Deichmann U, Lerner-Lam AL, Arnold M, Agwe J, Buys P, Kjekstad O, Lyon B, Yetman G (2005) Natural disaster hotspots: a global risk analysis. Disaster risk management series, vol 5. The World Bank, Washington, DC

Ermini L, Casagli N (2003) Prediction of the behavior of landslide dams using a geomorphological dimensionless index. Earth Surf Process Landf 28(1):31-47

Farina P, Colombo D, Fumagalli A, Marks F, Moretti S (2006) Permanent scatterers for landslide investigations: outcomes from the ESA-SLAM project. Eng Geol 88:200-217

Farina P, Casagli N, Ferretti A (2007) Radar-interpretation of InSAR measurements for landslide investigations in civil protection practices. In: Proceedings of 1st North American landslide conference, Vail, Colorado, pp 272-283

Ferretti A, Prati C, Rocca F (2000) Nonlinear subsidence rate estimation using permanent scatterers in differential SAR interferometry. IEEE Trans Geosci Remote Sens 38:2202-2212

Ferretti A, Prati C, Rocca F (2001) Permanent scatterers InSAR interferometry. IEEE Trans Geosci Remote Sens 39:8-20 
Ferretti A, Savio G, Barzaghi R, Borghi A, Musazzi S, Novali F, Prati C, Rocca F (2007a) Submillimeter accuracy of InSAR time series: experimental validation. IEEE Trans Geosci Remote Sens 45(5):1142-1153

Ferretti A, Fumagalli A, Novali F, Prati C, Rocca F, Rucci A (2011) A new algorithm for processing interferometric data-stacks: SqueeSAR ${ }^{\mathrm{TM}}$. IEEE Trans Geosci Remote Sens 99:1-11

Ferretti A, Savio G, Barzaghi R, Borghi A, Musazzi S, Novali F, Prati C, Rocca F (2007b) Submillimeter accuracy of InSAR time series: experimental validation. IEEE Trans Geosci Remote Sens 45(5):1142-1153

Frattini P, Crosta G, Carrara A (2010) Techniques for evaluating the performance of landslide susceptibility models. Eng Geol 111:62-72

Frodella W, Ciampalini A, Gigli G, Lombardi L, Raspini F, Nocentini M, Scardigli C, Casagli N (2016) Synergic use of satellite and ground based methods for the San Leo rock cliff monitoring. Geomorphology 264:80-94

Fruneau B, Achache J, Delacourt C (1996) Observation and modelling of the Saint-Etienne-de-Tinée landslide using SAR interferometry. Tectonophysics 265(3):181-190

Guzzetti F (2000) Landslide fatalities and the evaluation of landslide risk in Italy. Eng Geol 58:89-107

Guzzetti F, Carrara A, Cardinali M, Reichenbach P (1999) Landslide hazard evaluation: a review of current techniques and their application in a multi-scale study, Central Italy. Geomorphology 31:181-216

Guzzetti F, Galli M, Reichenbach P, Ardizzone F, Cardinali M (2006) Landslide hazard assessment in the Collazzone area, Umbria, central Italy. Nat Hazards Earth Syst Sci 6:115-131

Guzzetti F, Mondini AC, Cardinali M, Fiorucci F, Santangelo M, Chang KT (2012) Landslide inventory maps: new tools for an old problem. Earth Sci Rev 112:42-66

Hervás J (ed) (2013) Lessons learnt from landslide disasters in Europe. European Commission. Nedies Project, Joint Research Centre, Institute for the Protection and the Security of the Citizen, Technological and Economic Risk Management Unit

Hölbling D, Füreder P, Antolini F, Cigna F, Casagli N, Lang S (2012) A semi-automated object-based approach for landslide detection validated by persistent scatterer interferometry measures and landslide inventories. Remote Sens 4:1310-1336

IGOS Geohazards (2004) Geohazards theme report: for the monitoring of our environment from space and from earth. European Space Agency Publication, p 55

Iovine G, Petrucci O, Rizzo V, Tansi C (2006) The March 7th 2005 Cavallerizzo (Cerzeto) landslide in Calabria-Southern Italy. In: Proceeding of 10th IAEG international congress. Nottingham, 6-10 September

Kimura H, Yamaguchi Y (2000) Detection of landslide areas using satellite radar interferometry. Photogramm Eng Remote Sens 66(3):337-344

Longoni L, Papini M, Arosio D, Zanzi L, Brambilla D (2014) A new geological model for Spriana landslide. Bull Eng Geol Environ 73(4):959-970

Manconi A, Casu F, Ardizzone F, Bonano M, Cardinali M, de Luca C, Gueguen E, Marchesini I, Parise M, Vennari C et al (2014) Brief communication: rapid mapping of landslide events: the 3 December 2013 Montescaglioso landslide, Italy. Nat Hazards Earth Syst Sci 14:1835-1841

Massonnet D, Feigl KL (1998) Radar interferometry and its application to changes in the Earth's surface. Rev Geophys 36(4):441-500

Michel R, Avouac JP, Taboury J (1996) Measuring ground displacements from SAR amplitude images: application to the Landers earthquake. Geophys Res Lett 26(7):875-878

Nadim F, Kjekstad O, Peduzzi P, Herold C, Jaedicke C (2006) Global landslide and avalanche hotspots. Landslides 3(2):159-173

Notti D, Meisina C, Zucca F, Crosetto M, Montserrat O (2011) Factors that have an influence on time series. In: Proceedings of FRINGE workshop, ESA-ESRIN, Frascati, pp 19-23

Pagliara P, Basile G, Corazza A, Cara P, Duro A, Manfré B, Onori R, Proietti C, Sansone V (2014) Integration of Earth observation and ground-based HR data in the civil protection emergency cycle: the case of the DORIS project. Mathematics of planet Earth. Springer, Heidelberg, pp 263-266

Paradella WR, Ferretti A, Mura JC, Colombo D, Gama FF, Tamburini A, Santos AR, Novali F, Galo M, Camargo PO et al (2015) Mapping surface deformation in open pit iron mines of Carajás Province (Amazon Region) using an integrated SAR analysis. Eng Geol 193:61-78

Petley DN (2010) On the impact of climate change and population growth on the occurrence of fatal landslides in South, East and SE Asia. Q J Eng Geol Hydrogeol 43:487-496

Petley D (2012) Global patterns of loss of life from landslides. Geology 40(10):927-930

Raspini F, Moretti S, Casagli N (2013) Landslide mapping using SqueeSAR data: Giampilieri (Italy) case study. Landslide science and practice. Springer, Heidelberg, pp 147-154 
Raspini F, Moretti S, Fumagalli A, Rucci A, Novali F, Ferretti A, Prati C, Casagli N (2014) The COSMOSkyMed constellation monitors the costa concordia wreck. Remote Sens 6:3988-4002

Righini G, Pancioli V, Casagli N (2012) Updating landslide inventory maps using persistent scatterer interferometry (PSI). Int J Remote Sens 33(7):2068-2096

Rosen PA, Hensley S, Joughin IR, Li FK, Madsen SN, Rodriguez E, Goldstein RM (2000) Synthetic aperture radar interferometry. Proc IEEE 88(3):333-382

Salvati P, Bianchi C, Rossi M, Guzzetti F (2010) Societal landslide and flood risk in Italy. Nat Hazards Earth Syst Sci 10(3):465-483

Salvati P, Rossi M, Bianchi C, Guzzetti F (2015) Landslide risk to the population of Italy and its geographical and temporal variations. In: Chavez M, Ghil M, Urrutia-Fucugauchi J (eds) Extreme events: observations, modeling, and economics. Wiley, Hoboken

Schuster RL, Fleming RW (1986) Economic losses and fatalities due to landslides. Bull As Eng Geol 23(1):11-28

Singleton A, Li Z, Hoey T, Muller JP (2014) Evaluating sub-pixel offset techniques as an alternative to D-InSAR for monitoring episodic landslide movements in vegetated terrain. Remote Sens Environ $147: 133-144$

Strozzi T, Luckman A, Murray T, Wegmuller U, Werner CL (2002) Glacier motion estimation using SAR offset-tracking procedures. IEEE Trans Geosci Remote Sens 40:2384-2391

Tofani V, Raspini F, Catani F, Casagli N (2013) Persistent Scatterer Interferometry (PSI) technique for landslide characterization and monitoring. Remote Sens 5:1045-1065

Tomás R, Li Z, Lopez-Sanchez JM, Liu P, Singleton A (2015) Using wavelet tools to analyse seasonal variations from InSAR time-series data: a case study of the Huangtupo landslide. Landslides 13(3):437-450

Tralli DM, Blom RG, Zlotnicki V, Donnellan A, Evans DL (2005) Satellite remote sensing of earthquake, volcano, flood, landslide and coastal inundation hazards. ISPRS J Photogramm Remote Sens 59(4):185-198

Trigila A, Iadanza C, Munafò M, Marinosci I (2014) Population exposed to landslide and flood risk in Italy. In: Lollino G, Manconi A, Guzzetti F, Culshaw M, Bobrowsky P, Luino F (eds) Engineering geology for society and territory, vol 5. Springer, Switzerland, pp 843-848 